\title{
Variant Aldehyde Dehydrogenase $2(A L D H 2 * 2)$ in East Asians Interactively Exacerbates Tobacco Smoking Risk for Coronary Spasm - Possible Role of Reactive Aldehydes -
}

\author{
Yuji Mizuno, MD, PhD; Seiji Hokimoto, MD, PhD; Eisaku Harada, MD, PhD; \\ Kenji Kinoshita, PhD; Michihiro Yoshimura, MD, PhD; Hirofumi Yasue, MD, PhD
}

\begin{abstract}
Background: Coronary spastic angina (CSA) is common among East Asians and tobacco smoking (TS) is an established risk factor for CSA. Aldehyde dehydrogenase 2 (ALDH2) plays a key role in removing reactive toxic aldehydes and a deficient variant ALDH2 genotype $\left(A L D H 2^{*} 2\right)$ is prevalent among East Asians. We examined the interaction between TS and $A L D H 2^{*} 2$ as a risk factor for CSA to better understand the disease pathogenesis.
\end{abstract}

Methods and Results: The study subjects comprised 410 patients (258 men, 152 women; mean age, 66.3 \pm 11.5 ) in whom intracoronary injection of acetylcholine was performed on suspicion of CSA. ALDH2 genotyping was performed by direct application of the Taqman polymerase chain reaction system. Of the study subjects, 244 had CSA proven and 166 were non-CSA. The frequencies of male sex, $A L D H 2^{\star} 2$, alcohol flushing syndrome, TS, coronary organic stenosis, and plasma levels of uric acid were higher $(\mathrm{P}<0.001, \mathrm{P}<0.001, \mathrm{P}<0.001, \mathrm{P}<0.001, \mathrm{P}<0.001$, and $\mathrm{P}=0.015$, respectively) and that of high-density lipoprotein cholesterol lower $(\mathrm{P}=0.002)$ in the $\mathrm{CSA}$ than non-CSA group. Multivariable logistic regression analysis revealed that $A L D H 2{ }^{*} 2$ and TS were significant risk factors for CSA ( $\mathrm{P}<0.001$ and $\mathrm{P}=0.002$, respectively). $A L D H 2 * 2$ exacerbated TS risk for CSA more than the multiplicative effects of each.

Conclusions: $A L D H 22^{*}$ synergistically exacerbates TS risk for CSA, probably through aldehydes.

Key Words: Aldehyde dehydrogenase 2; Coronary spastic angina; East Asians; Reactive aldehydes; Tobacco smoking

$\mathrm{C}$ oronary (artery) spasm plays an important role in the pathogenesis of ischemic heart disease, including unstable angina pectoris, acute myocardial infarction and sudden cardiac death. ${ }^{1-3}$ Tobacco smoking (TS) is the sole established environmental risk factor for coronary spasm. ${ }^{1-4}$ However, the precise mechanisms underlying coronary spasm and the role of TS in the pathogenesis of coronary spasm remain to be elucidated. Coronary spastic angina (CSA), or angina pectoris caused by coronary spasm (also called vasospastic angina), is a common disease among East Asians, including Japanese..$^{1-5}$ Aldehyde dehydrogenase 2 (ALDH2) plays a central role in removing toxic aldehydes, including not only alcohol (ethanol)-derived acetaldehyde but also 4-hydoxy-2 nonenal (4-HNE) and malondialdehyde derived from lipid peroxidation or acrolein from TS. ${ }^{68}$ Carriers of the variant $A L D H 2$ or $A L D H 2 * 2$ (Glu504Lys) genotype have defi- cient enzymatic activity and comprise up to $40 \%$ of East Asians but are virtually non-existent in other populations of the world. ${ }^{8-10} A L D H 2 * 2$ exerts a dominant negative effect over wild-type $A L D H 2 * 1 / * 1$, and the heterozygote $A L D H 2 * 1 / * 2$ shows severely reduced, and the homozygote ALDH $2 * 2 / * 2$ negligible, ALDH2 activity. ${ }^{8}$ The carriers of $A L D H 2 * 2$ thus manifest alcohol flushing syndrome (AFS), including facial flushing, headache, nausea, and palpitation on intake of small amounts of alcohol caused by accumulation of acetaldehyde. ${ }^{\mathbf{8}-10} \mathrm{We}$ and others have reported that CSA can be induced by alcohol ingestion, particularly in those with AFS. ${ }^{11-13}$ We also have reported that $A L D H 2 * 2$ is a risk factor for CSA. ${ }^{14}$ The purpose of this study was to examine the interrelation between $A L D H 2 * 2$ and TS as a risk factor for CSA and thereby better understand the pathogenesis of CSA.

Received September 20, 2016; revised manuscript received October 19, 2016; accepted October 28, 2016; released online November 29, 2016 Time for primary review: 15 days

Division of Cardiovascular Medicine, Kumamoto Kinoh Hospital, Kumamoto Aging Research Institute, Kumamoto (Y.M., E.H., H.Y.); Department of Cardiovascular Medicine, Graduate School of Medical Sciences, Kumamoto University, Kumamoto (S.H.); School of Pharmaceutical Sciences, Mukogawa Women's University, Nishinomiya (K.K.); and Division of Cardiology, Department of Internal Medicine, The Jikei University School of Medicine, Tokyo (M.Y.), Japan

Mailing address: Yuji Mizuno, MD, PhD, Division of Cardiovascular Medicine, Kumamoto Aging Research Institute, 6-8-1 Yamamuro, Kita-ku, Kumamoto 860-8518, Japan. E-mail: mizuno@juryo.or.jp

ISSN-1346-9843 All rights are reserved to the Japanese Circulation Society. For permissions, please e-mail: cj@j-circ.or.jp 


\begin{tabular}{|c|c|c|c|}
\hline Variable & $\begin{array}{c}\text { CSA } \\
(n=244)\end{array}$ & $\begin{array}{c}\text { Non-CSA } \\
(n=166)\end{array}$ & $P$ value \\
\hline Age, years & $66.3 \pm 10.9$ & $66.3 \pm 12.1$ & 0.985 \\
\hline Sex (male), n (\%) & $173(70.9)$ & $85(51.2)$ & $<0.001$ \\
\hline $\mathrm{BMI}, \mathrm{kg} / \mathrm{m}^{2}$ & $24.3 \pm 3.5$ & $24.5 \pm 3.6$ & 0.584 \\
\hline Systolic BP, mmHg & $131.0 \pm 20.0$ & $133.4 \pm 23.0$ & 0.263 \\
\hline Diastolic BP, mmHg & $68.2 \pm 16.3$ & $67.6 \pm 17.9$ & 0.728 \\
\hline Albumin, $g / L$ & $41(39,43)$ & $41(39,43)$ & 0.551 \\
\hline hs-CRP, mg/L & $0.77(0.32,2.91)$ & $0.60(0.24,2.09)$ & 0.066 \\
\hline Glucose, mmol/L & $5.61(5.05,6.44)$ & $5.55(5.11,6.16)$ & 0.659 \\
\hline Triglycerides, $\mathrm{mmol} / \mathrm{L}$ & $1.37(0.99,1.98)$ & $1.25(0.89,1.87)$ & 0.113 \\
\hline $\mathrm{HDL}-\mathrm{C}, \mathrm{mmol} / \mathrm{L}$ & $0.58(0.50,0.72)$ & $0.65(0.55,0.79)$ & 0.002 \\
\hline LDL-C, mmol/L & $1.23(0.93,1.43)$ & $1.24(0.98,1.51)$ & 0.167 \\
\hline Uric acid, $\mu \mathrm{mol} / \mathrm{L}$ & $333(274,387)$ & $303(262,369)$ & 0.015 \\
\hline eGFR, $\mathrm{mL} / \mathrm{min} / 1.73 \mathrm{~m}^{2}$ & $68.2 \pm 16.3$ & $67.6 \pm 17.9$ & 0.728 \\
\hline Alcohol habit, n (\%) & $87 / 240(36.3)$ & $58 / 165(35.2)$ & 0.821 \\
\hline AFS, n (\%) & $134 / 209(64.1)$ & $60 / 148(40.5)$ & $<0.001$ \\
\hline \multicolumn{4}{|l|}{$A L D H 2$ genotype } \\
\hline$A L D H 2{ }^{*} 1{ }^{*} 1, \mathrm{n}(\%)$ & $111(45.5)$ & $114(68.7)$ & $<0.001$ \\
\hline$A L D H 2^{*} 2{ }^{*} 1, \mathrm{n}(\%)$ & $111(45.5)$ & $46(27.7)$ & $<0.001$ \\
\hline$A L D H 2^{*} 2 /{ }^{\star} 2, \mathrm{n}(\%)$ & $22(9.0)$ & $6(3.6)$ & 0.033 \\
\hline Smoker, n (\%) & $154(63.1)$ & $71(42.8)$ & $<0.001$ \\
\hline OCS, n (\%) & $120(49.2)$ & $51(30.7)$ & $<0.001$ \\
\hline
\end{tabular}

AFS, alcohol flushing syndrome; ALDH2, aldehyde dehydrogenase 2; BMI, body mass index; BP, blood pressure; CSA, coronary spastic angina; eGFR, estimated glomerular filtration rate; HDL-C, high-density lipoprotein cholesterol; hs-CRP, high-sensitivity C-reactive protein; LDL-C, low-density lipoprotein cholesterol; OCS, organic coronary stenosis.

\section{Methods}

\section{Study Subjects}

The study subjects consisted of 410 Japanese patients ( 258 men, 152 women; mean age, 66.3 \pm 11.5 ) who between January, 2010 and August 2016 underwent coronary angiography and intracoronary injection of acetylcholine (ACh) on suspicion of CSA because of episodes of chest discomfort occurring at rest. CSA were diagnosed in 244 patients (173 men, 81 women; mean age, 66.3 \pm 10.9$)$ and non-CSA in 166 patients ( 85 men, 81 women; mean age $66.3 \pm 12.1)$ on the basis of angiographically documented coronary spasm. Patients with acute myocardial infarction, 3 -vessel organic disease, left main trunk lesion, uncontrolled arrhythmias, heart failure, resting blood pressure $>180 / 110 \mathrm{mmHg}$, acute systemic illness, and hepatic or renal insufficiency or other severe conditions were excluded from the study. All vasoactive medications, including calcium-channel blockers, $\beta$-receptor blockers, angiotensinconverting enzyme inhibitors, angiotensin II receptors blockers and statins, were withdrawn for at least 3 days before angiography except for nitroglycerin (GTN) used for attacks.

This study was conducted in accordance with the Declaration of Helsinki and approved by the institutional ethics committees and written informed consent was given by each patient.

\section{Angiographic Documentation of Coronary Spasm}

Coronary spasm was defined as a transient total or subtotal occlusion or severe diffuse vasoconstriction of an epicardial coronary artery associated with ischemic changes on ECG. ${ }^{1}$ Coronary spasm was documented by intracoronary injection of ACh (Daiichi-Sankyo Co., Tokyo, Japan) after diagnostic catheterization in the morning.,114 ACh was infused in incremental doses of 20,50 and $100 \mu \mathrm{g}$ into the left coronary artery, and then 20 and, $50 \mu \mathrm{g}$ into the right coronary artery depending on the vascular reactivity of each subject under continuous monitoring by 12-lead ECG and blood pressure with a temporary pacemaker inserted in the right ventricle. Coronary spasm induced by this method usually disappears spontaneously within 1 to $2 \mathrm{~min}$, and both the left and right coronary arteries can be examined separately unless severe spasm occurs in the left coronary artery, necessitating prompt injection of GTN or isosorbide dinitrate into the artery. Finally, GTN or isosorbide dinitrate was infused to relieve spasm and allow examination of organic lesions. Significant organic coronary stenosis was defined as $>50 \%$ luminal diameter.

\section{Genotypes}

Single nucleotide polymorphism genotyping of $A L D H 2$ (Glu504Lys; rs671) was performed on whole blood without DNA extraction using the TaqMan assay on an ABI 7300 Real Time PCR System (Applied Biosystems, Foster City, CA, USA). ${ }^{15}$ The mixture was $20 \mu \mathrm{L}$, consisting of $10 \mu \mathrm{L}$ of a Thunderbird Probe qPCR Mix (QPS-101, Toyobo, Osaka, Japan), $0.4 \mu \mathrm{L}$ of a $50 \times \mathrm{ROX}$ reference dye (Toyobo), $1 \mu \mathrm{L}$ of a $20 \times \mathrm{ALDH} 2$ TaqMan Probe and ALDH2 Primer Mix (C_11703892_10, ABI), $2 \mu \mathrm{L}$ of PCR product, and $6.6 \mu \mathrm{L}$ of distilled water. The thermal cycling process was performed according to the manufacturer's conditions: $2 \mathrm{~min}$ at $50^{\circ} \mathrm{C}, 10 \mathrm{~min}$ at $95^{\circ} \mathrm{C}, 40$ cycles of denaturation at $95^{\circ} \mathrm{C}$ for $15 \mathrm{~s}$, and annealing and extension at $60^{\circ} \mathrm{C}$ for $1 \mathrm{~min}$. The results were analyzed by ABI Prism 7300 SDS software. The genotyping was performed with blinded 


\begin{tabular}{|c|c|c|c|}
\hline Variable & $\begin{array}{c}\text { Variant } A L D H 2 * 2 \\
(n=185)\end{array}$ & $\begin{array}{c}\text { Wild-type } A L D H 2 * 1 /{ }^{*} 1 \\
(\mathrm{n}=225)\end{array}$ & $P$ value \\
\hline Age, years & $66.6 \pm 10.8$ & $66.0 \pm 11.8$ & 0.564 \\
\hline Sex (male), n (\%) & $115(62.2)$ & $142(63.1)$ & 0.675 \\
\hline $\mathrm{BMI}, \mathrm{kg} / \mathrm{m}^{2}$ & $24.3 \pm 3.5$ & $24.4 \pm 3.6$ & 0.689 \\
\hline Systolic BP, mmHg & $131.6 \pm 19.8$ & $132.2 \pm 22.4$ & 0.806 \\
\hline Diastolic BP, mmHg & $75.2 \pm 14.2$ & $76.8 \pm 16.2$ & 0.292 \\
\hline Albumin, $g / L$ & $41(38,43)$ & $41(39,43)$ & 0.430 \\
\hline hs-CRP, mg/L & $0.81(0.30,2.72)$ & $0.62(0.25,2.13)$ & 0.140 \\
\hline Glucose, $\mathrm{mmol} / \mathrm{L}$ & $5.44(5.00,6.16)$ & $5.77(5.11,6.66)$ & 0.012 \\
\hline Triglycerides, $\mathrm{mmol} / \mathrm{L}$ & $1.26(0.96,1.87)$ & $1.40(0.95,1.99)$ & 0.479 \\
\hline $\mathrm{HDL}-\mathrm{C}, \mathrm{mmol} / \mathrm{L}$ & $1.41(1.13,1.71)$ & $1.45(1.22,1.68)$ & 0.299 \\
\hline LDL-C, mmol/L & $2.90(2.22,3.41)$ & $2.71(2.10,3.36)$ & 0.135 \\
\hline Uric acid, $\mu \mathrm{mol} / \mathrm{L}$ & $309(262,363)$ & $333(280,387)$ & 0.011 \\
\hline eGFR, $\mathrm{mL} / \mathrm{min} / 1.73 \mathrm{~m}^{2}$ & $67.1 \pm 15.9$ & $68.7 \pm 17.8$ & 0.355 \\
\hline Alcohol habit, n (\%) & $29 / 183(15.8)$ & 116/222 (52.3) & $<0.001$ \\
\hline Male, n (\%) & $26 / 113(23.0)$ & $97 / 141(68.9)$ & $<0.001$ \\
\hline Female, n (\%) & $3 / 70(4.3)$ & $19 / 81(23.5)$ & 0.001 \\
\hline AFS, n (\%) & 153/164 (93.3) & $41 / 193(21.2)$ & $<0.001$ \\
\hline Smoker, n (\%) & $103(55.7)$ & $122(54.2)$ & 0.769 \\
\hline CSA, n (\%) & $133(71.9)$ & $111(49.3)$ & $<0.001$ \\
\hline OCS, n (\%) & $81(43.8)$ & $90(40.0)$ & 0.439 \\
\hline
\end{tabular}

Abbreviations as in Table 1.

\begin{tabular}{|lccccc|}
\hline \multicolumn{7}{l}{ Table 3. Multivariable Logistic Regression Analysis for CSA } & & & \\
& OR & SE & $\mathbf{z}$ & $\mathbf{P}>|\mathbf{z}|$ & $\mathbf{9 5 \%}$ Cl \\
ALDH2*2 & 3.0311 & 0.6954 & 4.83 & $<0.001$ & $1.9334-4.7520$ \\
TS & 2.0606 & 0.4740 & 3.14 & 0.002 & $1.3128-3.2345$ \\
OCS & 2.0164 & 0.4667 & 3.03 & 0.002 & $1.2810-3.1740$ \\
Uric acid $(>6.0 \mathrm{mg} / \mathrm{dL})$ & 1.3168 & 0.3265 & 1.11 & 0.267 & $0.8100-2.1407$ \\
Age $(>65$ years) & 1.1945 & 0.2714 & 0.78 & 0.434 & $0.7653-1.8646$ \\
HDL-C $(>60 \mathrm{mg} / \mathrm{dL})$ & 0.8678 & 0.2070 & -0.59 & 0.552 & $0.5438-1.3851$ \\
\hline
\end{tabular}

$A L D H 2 * 2, A L D H 2$ variant genotype; $\mathrm{Cl}$, confidence interval; OR, odds ratio; SE, standard error; TS, tobacco smoking. Other abbreviations as in Table 1.

identification of the study subjects. Allele frequencies were determined by direct gene counting and genotype distributions were checked for departure from Hardy-Weinberg equilibrium using the Pearson Chi-square test.

\section{Questionnaire Survey}

The subjects were asked to fill out a simple questionnaire concerning alcohol flushing on alcohol intake, alcohol drinking and smoking habits. A habitual drinker was defined as drinking alcohol on more than 5 days a week. Alcohol flushing was defined as a current or a history of facial flushing immediately after drinking a glass of beer. Smokers were defined as current or past smokers.

\section{Blood Chemistry Measurements}

Blood samples for measurement of clinical chemistry and other data were collected after an overnight fast with the patients in a supine position. The biochemical and other analyses were done using standard laboratory procedures.

\section{Statistical Analysis}

The associations between the ALDH2 genotype or smoking status with CSA were calculated as odds ratios (ORs) and $95 \%$ confidence intervals (95\% CIs) using logistic regression analysis. The interactive or combined effects between the ALDH2 genotype and TS on CSA were analyzed using a logistic regression model and likelihood-ratio test. The OR of $A L D H 2 * 2$ and TS for coronary spasm were compared with non-smokers with the wild-type $A L D H 2 * 1 / * 1$ as the reference group. The baseline clinical data are expressed as the mean \pm SD or median $(25$ th, 75 th percentile) for continuous variables and differences within the group were evaluated with an unpaired t-test or the Mann-Whitney rank sum test. For discrete variables, data are expressed as counts and percentages and were analyzed with the Chi-square test. Correlations between variables were assessed using Spearman's rank correlation coefficient. Variables that were not statistically significant (i.e., $\mathrm{P}>0.05$ ) were excluded from further analyses. A multiple logistic regression analysis was performed to determine the 


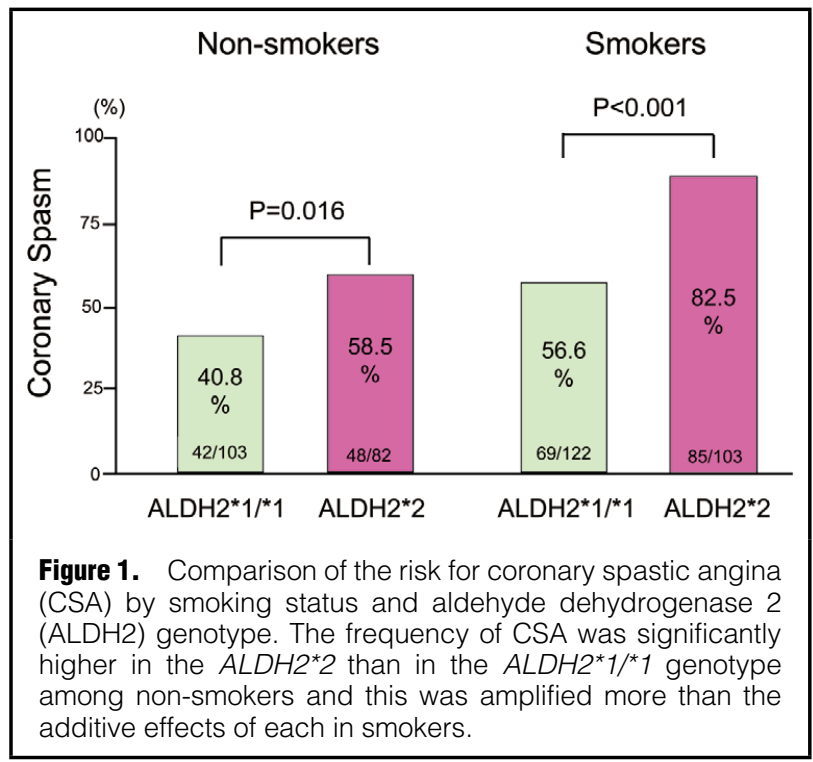

predictors of CSA. Predictor variables were included on the basis of theoretical grounds, the results of a bivariate analysis and collinearity. A two-tailed value of $\mathrm{P}<0.05$ was considered to be statistically significant. The analyses were done using the STATA software program (STATA 11.0, STATA Corp., College Station, TX, USA).

\section{Results}

Table 1 compares the clinical characteristics of the CSA and non-CSA groups. There were no significant differences in the clinical features of both groups except for the frequencies of male sex, AFS, smoker, coronary organic stenosis, and plasma uric acid levels, which were all higher $(\mathrm{P}<0.001, \mathrm{P}<0.001, \mathrm{P}<0.001, \mathrm{P}<0.001$, and $\mathrm{P}=0.015$, respectively) and the plasma levels of high-density lipoprotein cholesterol (HDL-C), which was lower $(\mathrm{P}=0.002)$ in the CSA than in the non-CSA group. The genotype distributions did not depart from Hardy-Weinberg equilibrium for $A L D H 2$ genes $\left(\chi^{2}=0.60, \mathrm{P}=0.44\right.$ for CSA group and $\chi^{2}=0.25, \mathrm{P}=0.62$ for non-CSA group). There was a significant overall difference in genotype distribution of $A L D H 2$ between the CSA and non-CSA groups $\left(\chi^{2}=22.3, \mathrm{P}<0.001\right)$. The frequencies of the $A L D H 2 * 1 / * 1, A L D H 2 * 1 / * 2$ and $A L D H 2 * 2 / * 2$ genotypes are shown in Table 1 and the frequency of the $A L D H 2 * 2$ allele was thus $41.1 \%$ in the CSA group and $20.3 \%$ in the non-CSA group, respectively. The allele frequency of $A L D H 2 * 2$ in the general population is $23.5 \%(247 / 1,050)$ in Kumamoto and $24.3 \%(183 / 752)$ in Tokyo, Japan. ${ }^{9}$ Thus, the frequency of $A L D H 2 * 2$ allele in the CSA group was higher and that in the non-CSA group lower than in the general population of Japan. These findings imply that $A L D H 2 * 2$ is causally associated with CSA because alleles are randomly assigned at conception according to Mendel's law. ${ }^{16}$ The findings also indicate that ALDH2*2 genotypes exist mainly as heterozygotes $(A L D H 2 * 1 / * 2)$. We therefore combined heterozygotes $(A L D H 2 * 1 / * 2)$ and homozygotes of $(A L D H 2 * 2 / * 2)$ as a single category of $A L D H 2 * 2$ and compared it with wild homozygotes $A L D H 2 * 1 / * 1$ in the analyses, assuming a dominant mode of inheritance for $A L D H 2 * 2$.

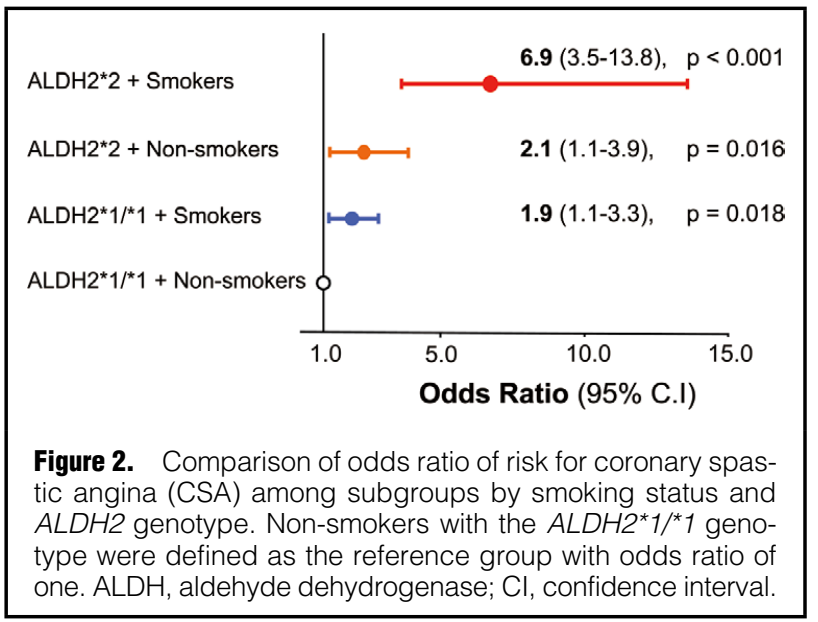

Table 2 compares the clinical characteristics of the wild $(A L D H 2 * 1 / * 1)$ and variant genotype ( $A L D H 2 * 2)$ groups. There were no significant differences in the clinical features of the 2 groups, except that frequencies of CSA and AFS were higher $(71.9 \%$ vs. $49.3 \%, \mathrm{OR}=2.6[95 \% \mathrm{CI}, 1.7-4.0]$, $\mathrm{P}<0.001$ and $93.3 \%$ vs. $21.2 \%, \mathrm{OR}=51.6[95 \% \mathrm{CI}, 25.5-$ 104.1], $\mathrm{P}<0.001$, respectively) and overall alcohol habit was lower $(15.8 \%$ vs. $52.3 \%, \mathrm{OR}=0.2$ [95\% CI, $0.1-0.3$ ], $\mathrm{P}<0.001)$ in the $A L D H 2 * 2$ group than in the $A L D H 2 * 1 / * 1$ group. Smokers had a significantly higher prevalence of CSA (63.1\% vs. $48.9 \%$, OR=2.3 [95\% CI, 1.5-3.4], P<0.001) than non-smokers. AFS was significantly associated with ALDH2*2 (93.3\% vs. 21.2\%; OR, 51.6 [95\% CI, 25.5104.1]; $\mathrm{P}<0.0001)$, with sensitivity of $93.3 \%(153 / 164)$ and specificity of $78.8 \%(152 / 193)$ for $A L D H 2 * 2$. AFS thus may be useful for detecting $A L D H 2 * 2$.

The multivariable logistic regression analysis for CSA included age ( $>65$ years), TS, $A L D H 2 * 2$ genotype, coronary organic stenosis, and the plasma levels of HDL-C $(>60 \mathrm{mg} / \mathrm{dL})$ and uric acid $(>6.0 \mathrm{mg} / \mathrm{dL})$ as independent variables. Because there was a highly significant association between $A L D H 2 * 2$ genotype and AFS, and between TS and male sex $[\mathrm{P}<0.0001$ and $\mathrm{P}<0.0001$, respectively], AFS and sex were excluded as independent variables. The analysis revealed that $A L D H 2 * 2$ genotype, TS, and organic coronary stenosis (OCS) were significant risk factors for CSA $(\mathrm{OR}=3.0$ [95\% CI, 1.9-4.8], $\mathrm{P}<0.001$, $\mathrm{OR}=2.1,[95 \% \mathrm{CI}, 1.3-3.2], \mathrm{P}=0.002$, and $\mathrm{OR}=2.0,[95 \%$ CI, 1.3-3.2], $\mathrm{P}=0.002$, respectively) (Table 3).

$A L D H 2 * 2$ had a higher risk for CSA than $A L D H 2 * 1 / * 1$ in non-smokers $(58.5 \%$ vs. $40.8 \%, \mathrm{OR}=2.1$ [95\% CI, $1.2-$ 3.8], $\mathrm{P}=0.016)$ and exaggerated the risk in smokers $(82.5 \%$ vs. $56.6 \%, \mathrm{OR}=4.4[95 \% \mathrm{CI}, 2.1-9.2], \mathrm{P}<0.001$, respectively) (Figure 1). Smokers with $A L D H 2 * 1 / * 1$ and nonsmokers with $A L D H 2 * 2$ had an OR of $1.9(95 \% \mathrm{CI}$, $1.1-3.3 ; \mathrm{P}<0.001)$ and $2.1(95 \% \mathrm{CI}, 1.1-3.9 ; \mathrm{P}<0.001)$, respectively, compared with non-smokers with $A L D H 2 * 1 / * 1$ as the reference $(\mathrm{OR}=1.0)$ (Figure 2, Table 4A). Smokers with $A L D H 2 * 2$ would thus be expected to have the additive or multiplicative effects of $A L D H 2 * 2$ and TS on CSA or an OR of $1.9 \times 2.1=4.0$ as compared with non-smokers with $A L D H 2 * 1 / * 1$ as the reference $(\mathrm{OR}=1.0) .{ }^{17,18}$ However, the results revealed that smokers with $A L D H 2 * 2$ had an OR of 6.9 (95\% CI, 3.5-13.8; $\mathrm{P}<0.001)$, which was higher than the product of each or their interaction on the 


\begin{tabular}{|lccc|}
\hline \multicolumn{4}{|c|}{ Table 4. (A) Prevalence of Provoked CSA and (B) ORs for CSA Among Subgroups Divided by ALDH 2} \\
Genotype and TS & Non-smoker & Smoker & Total \\
A & & & \\
ALDH2 ${ }^{*} 1$ & $42 / 103(0.41)$ & $69 / 122(0.57)$ & $111 / 225(0.49)$ \\
ALDH2 2 & $48 / 82(0.59)$ & $85 / 103(0.83)$ & $133 / 185(0.72)$ \\
Total & $90 / 185(0.49)$ & $154 / 225(0.68)$ & $244 / 410(0.60)$ \\
B & & & \\
ALDH2*1*1 & 1 (Ref.) & 1.9 & \\
ALDH2*2 & 2.1 & 6.9 & \\
\hline
\end{tabular}

(A) Data in parentheses indicate ratio. (B) ALDH2 $2^{*} 1^{*} 1$ and non-smoker subgroup defined as reference with OR of one. Interaction on the multiplicative scale: $6.9 / 2.1 \times 1.9=1.7(95 \% \mathrm{Cl} 1.3-2.3, \mathrm{P}<0.001)>1.0$. Abbreviations as in Tables 1,3.

\begin{tabular}{|c|c|c|c|c|c|}
\hline & OR & SE & $z$ & $P>|z|$ & $95 \% \mathrm{Cl}$ \\
\hline \multicolumn{6}{|l|}{ Model A } \\
\hline$A L D H 2 * 2$ & 2.725 & 0.598 & 4.57 & 0.000 & $1.772-4.191$ \\
\hline TS & 2.268 & 0.488 & 3.81 & 0.000 & $1.488-3.456$ \\
\hline OCS & 2.087 & 0.462 & 3.32 & 0.001 & $1.352-3.221$ \\
\hline \multicolumn{6}{|l|}{ Model B } \\
\hline$A L D H 2 * 2$ & 0.767 & 0.521 & 1.93 & 0.054 & $0.991-3.151$ \\
\hline TS & 1.609 & 0.427 & 1.79 & 0.073 & $0.956-2.709$ \\
\hline$A L D H 2 * 2+T S$ & 2.557 & 1.127 & 2.13 & 0.033 & $1.078-6.064$ \\
\hline OCS & 2.003 & 0.446 & 3.12 & 0.002 & $1.294-3.100$ \\
\hline \multicolumn{6}{|l|}{ Model C } \\
\hline$A L D H 2 * 2$ & 1.759 & 0.518 & 1.92 & 0.055 & $0.988-3.134$ \\
\hline TS & 1.611 & 0.427 & 1.80 & 0.072 & $0.958-2.710$ \\
\hline$A L D H 2 * 2+T S$ & 2.248 & 1.116 & 1.63 & 0.103 & $0.849-5.950$ \\
\hline OCS & 1.905 & 0.460 & 2.67 & 0.008 & $1.187-3.057$ \\
\hline$A L D H 2 * 2+T S+O C S$ & 1.405 & 0.895 & 0.53 & 0.593 & $0.403-4.896$ \\
\hline
\end{tabular}

Likelihood-ratio test (LR): $A L D H 2{ }^{*} 2+T S$ was included as interaction term for CSA risk in model $\mathrm{B}$. LR $x^{2}=4.64$, $\mathrm{P}=0.031$. $A L D H 2 * 2+\mathrm{TS}+\mathrm{OCS}$ was included as interaction term for CSA risk in model $\mathrm{C}$. $\mathrm{LR} X^{2}=0.29, \mathrm{P}=0.59$. Abbreviations as in Tables 1,3 .

multiplicative scale: $6.9 / 1.9 \times 2.1=1.73(95 \%$ CI, $1.3-2.3)$ $>1.0, \mathrm{P}<0.001$ (Figure 2, Table 4B). This implies that $A L D H 2 * 2$ interactively amplified TS risk for CSA on the multiplicative scale. When $A L D H 2 * 2$ plus TS (interaction term) was entered in the multivariable logistic regression analysis for CSA, it became statistically significant, with OR 2.6 [95\% CI, 1.1-6.1, P=0.033], whereas the main effects or the effect of $A L D H 2 * 2$ and TS became insignificant $(\mathrm{P}=0.054$ and 0.073 , respectively) with OCS remaining significant $(\mathrm{P}=0.002)$ as a risk factor for CSA (model $\mathrm{B}$ in Table 5). Thus, the likelihood-ratio test was significant $(X 2=4.64, \mathrm{P}=0.031)$, indicating that $A L D H 2 * 2$ interactively exacerbated the TS risk for CSA more than the multiplicative effect of each considered separately. ${ }^{17,18}$

The frequency of OCS was significantly higher in the CSA than in the non-CSA group $(\mathrm{P}<0.001)$. However, the presence of OCS did not significantly affect the interaction of $A L D H 2 * 2$ with TS in CSA on the likelihood-ratio test $(\mathrm{P}=0.59)$ as shown in model $\mathrm{C}$ of Table 5 . Transient atrial fibrillation, hypotension, and pacing failure occurred in 48 , 15 , and 2 of the study subjects, respectively, but no serious complications were observed with the ACh provocation test for CSA in the present study.

\section{Discussion}

The present study demonstrates that the $A L D H 2 * 2$ genotype is significantly associated with CSA in East Asians, confirming the results of our previous study in a larger number of study subjects. ${ }^{14}$ Because genotypes are assigned randomly at conception, independently of possible confounding factors, according to the Mendel's law (Mendelian randomization) ${ }^{16}$ it is reasonable to consider the $A L D H 2 * 2$ genotype as causally associated with CSA. Our multivariable logistic regression analysis revealed that the $A L D H 2 * 2$ genotype, as well as TS, is a significant risk factor for CSA, confirming the results of our previous study in a larger number of study subjects. ${ }^{14}$ The present study therefore may explain at least partially why CSA is common among East Asians. However, the fact that $49 \%$ of the wild-type $A L D H 2 * 1 / * 1$ carriers exhibited CSA (Table 2) implies that factors other than $A L D H 2 * 2$ are involved in the pathogenesis of CSA. Indeed, previous studies report that CSA is associated with genetic polymorphisms of endothelial nitric oxide synthase, ${ }^{19}$ paraoxonase, ${ }^{20}$ NADH/NADPH oxidase p22 phox, stromelysin-1, interleukin- $6,{ }^{21}$ and phospholipase- $\delta 1^{\mathbf{2 2}}$ as well as TS. ${ }^{\mathbf{1 - 4 2 1}} \mathrm{It}$ is therefore likely that CSA is a multifactorial disorder involving both TS 


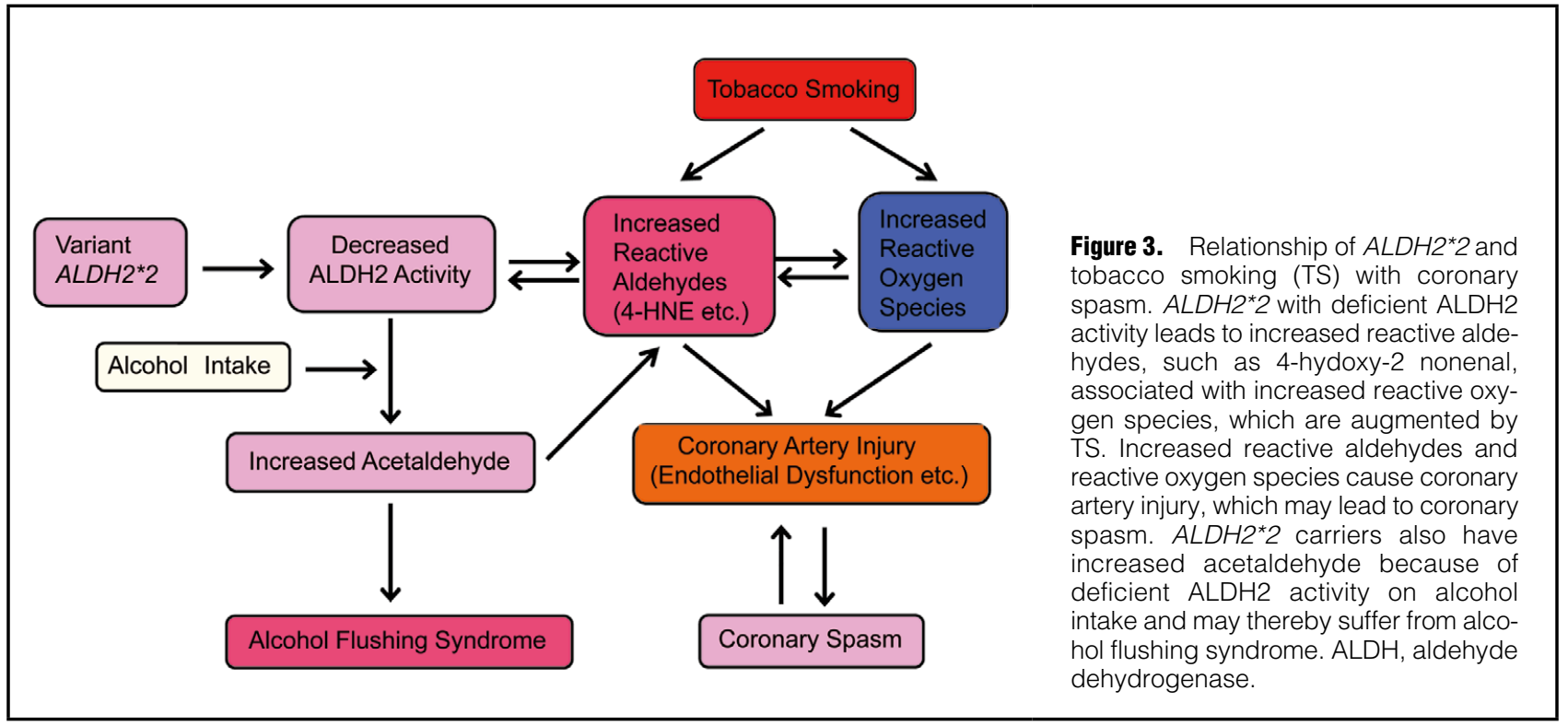

and genetic factors. However, the $A L D H 2 * 2$ genotype is unique because is specifically prevalent among East Asians, in whom CSA is prevalent. TS is a well-established risk factor for CSA. $\mathbf{1 , 3 , 4 , 2 1}$ However, the mechanisms underlying the involvement of TS in CSA remain to be elucidated. It is interesting to note in this connection that coronary risk factors other than TS, such as hypertension, dyslipidemia etc., are not risk factors for CSA and that the presence of OCS did not significantly affect the interaction of $A L D H 2 * 2$ with TS on provoking coronary spasm in this study. These findings suggest that the pathogenesis of coronary spasm may be distinct from that of atherosclerosis, and that organic stenosis may be an innocent bystander rather than the culprit.,23 The present study further revealed that $A L D H 2 * 2$ interactively exacerbates the TS risk for coronary spasm more than the additive or multiplicative effects of each considered separately. ${ }^{17,18}$

\section{Clinical Implications}

Exposure of biological lipid membranes to reactive oxygen species (ROS) results in lipid peroxidation and generates numerous reactive aldehydes, which are more stable and diffuse greater distances than ROS and thereby propagate oxidative damage. ${ }^{6-8}$ ALDH2 eliminates not only alcoholderived acetaldehyde but also other reactive aldehydes including 4-HNE and malondialdehyde, derived from lipid peroxidation, and acrolein from TS, and thereby protects tissues and cells from oxidative damage. ${ }^{6-8}$ TS contains various reactive aldehydes and oxidants and also generates endogenous aldehydes by lipid peroxidation. ${ }^{24-29}$ It is therefore likely that $A L D H 2 * 2$ interacts with TS and exacerbates the risk for CSA by further increasing reactive aldehydes. Reactive aldehydes and ROS cause vascular damage, including endothelial dysfunction, increased ROS, smooth muscle proliferation, low-grade inflammation and thrombogenicity. ${ }^{6,7,30-32}$ All of these have been demonstrated to be present in patients with CSA.1,3,19-21,33,34

The rate of TS is higher among East Asians than Westerns. ${ }^{35}$ The present study therefore identifies deficient ALDH2 activity and hence increased reactive aldehydes and ROS as risk factors to be targeted for the treatment and prevention of CSA as illustrated in Figure 3. Chen and other workers recently showed that the novel small molecule activator of ALDH2, Alda-1, effectively restored the deficient activity of $A L D H 2 * 2$ in animal models., ${ }^{8,36}$ Accordingly, it is expected that this class of drug may prove to be a new therapeutic for CSA in the future. The present study also showed the high sensitivity and specificity of AFS for $A L D H 2 * 2$, which implies that AFS may be useful as a surrogate marker of $A L D H 2 * 2$ in the absence of genotyping.

\section{Study Limitations}

The number of study patients was small because the study was invasive and required a high degree of expertise. The study subjects were a select population who underwent coronary angiography on suspicion of CSA and this may have altered the relationship with $A L D H 2 * 2$. However, the presence or absence of CSA was strictly determined by angiographic documentation. The study subjects were limited to Japanese suspected of having CSA because of a genetic association study ${ }^{\mathbf{1 6}}$ and the results therefore may not necessarily be applicable to other populations. The frequencies of AFS and smoking or alcohol habit were assessed by questionnaire survey, and recall and subjective biases may have influenced the results. Aldehydes were not measured because they are highly reactive and many of them exist as adducts with proteins, DNA or lipids in tissues $^{6-8}$ and clinically applicable methods of measurement are not yet available.

\section{Conclusions}

$A L D H 2 * 2$ was associated with CSA and synergistically amplified and exacerbated the TS risk for CSA more than the multiplicative effect of each factor, probably through increasing reactive aldehydes. Reactive aldehydes therefore are involved in the pathogenesis of CSA and were identified as a target for the treatment and prevention of CSA. 


\section{Acknowledgments}

This study was supported in part by the Japan Heart Foundation, Tokyo, and the Japan Vascular Disease Research Foundation, Kyoto, Japan. We thank Ms. Yoshimi Tokunaga and the staff at the clinical laboratory of our institution for providing the laboratory data.

\section{Sources of Funding}

This study was supported in part by the Japan Heart Foundation, Tokyo, and the Japan Vascular Disease Research Foundation, Kyoto, Japan.

\section{Disclosures}

None.

\section{References}

1. Yasue H, Nakagawa H, Itoh T, Harada E, Mizuno Y. Coronary artery spasm: Clinical features, diagnosis, pathogenesis, and treatment. J Cardiol 2008; 51: 2-17.

2. Maseri A, Beltrame JF, Shimokawa H. Role of coronary vasoconstriction in ischemic heart disease and search for novel therapeutic targets. Circ J 2009; 73: 394-403.

3. JCS Joint Working Group. Guidelines for diagnosis and treatment of patients with vasospastic angina (coronary spastic angina) (JCS 2013): Digest version. Circ J 2014; 78: 2779-2801.

4. Morita S, Mizuno Y, Harada E, Nakagawa H, Morikawa Y, Saito Y, et al. Differences and interactions between risk factors for coronary spasm and atherosclerosis: Smoking, aging, inflammation, and blood pressure. Intern Med 2014; 53: 2663-2670.

5. Pristipino C, Beltrame JF, Finocchiaro ML, Hattori R, Fujita $\mathrm{M}$, Mongiardo R, et al. Major racial differences in coronary constrictor response between Japanese and Caucasians with recent myocardial infarction. Circulation 2000; 101: 1102-1108.

6. Hill BG, Bhatnagar A. Beyond reactive oxygen species: Aldehydes as arbitrators of alarm and adaptation. Circ Res 2009; 105: 1044-1046.

7. Singh S, Brocker C, Koppaka V, Chen Y, Jackson BC, Matsumoto A, et al. Aldehyde dehydrogenases in cellular responses to oxidative/electrophilic stress. Free Radic Biol Med 2013; 56: 89-101.

8. Chen CH, Ferreira JC, Gross ER, Mochly-Rosen D. Targeting aldehyde dehydrogenase 2: New therapeutic opportunities. Physiol Rev 2014; 94: 1-34.

9. Li H, Borinskaya S, Yoshimura K, Kal'ina N, Marusin A, Stepanov VA, et al. Refined geographic distribution of the oriental ALDH2*504Lys (nee 487Lys) variant. Ann Hum Genet 2009; 73: $335-345$.

10. Yokoyama A, Omori T, Yokoyama T. Alcohol and aldehyde dehydrogenase polymorphisms and a new strategy for prevention and screening for cancer in the upper aerodigestive tract in East Asians. Keio J Med 2010; 59: 115-130.

11. Takizawa A, Yasue H, Omote S, Nagao M, Hyon H, Nishida S, et al. Variant angina induced by alcohol ingestion. Am Heart $J$ 1984; 107: 25-27.

12. Seki T, Okayama H, Isoyama S, Kagaya Y, Shirato K, Munakata $\mathrm{K}$, et al. The role of alcohol dehydrogenase 2 and aldehyde dehydrogenase 2 genotypes in alcohol-induced vasospastic angina. Tohoku J Exp Med 1999; 187: 311-322.

13. Mizuno Y, Morita S, Harada E, Shono M, Morikawa Y, Murohara $\mathrm{T}$, et al. Alcohol flushing and positive ethanol patch test in patients with coronary spastic angina: Possible role of aldehyde dehydrogenase 2 polymorphisms. Intern Med 2013; 52: $2593-$ 2598.

14. Mizuno Y, Harada E, Morita S, Kinoshita K, Hayashida M, Shono M, et al. East Asian variant of aldehyde dehydrogenase 2 is associated with coronary spastic angina: Possible roles of reactive aldehydes and implications of alcohol flushing syndrome. Circulation 2015; 131: 1665-1673.

15. Hayashida M, Ota $T$, Ishii $M$, Iwao-Koizumi $K$, Murata $S$, Kinoshita K. Direct detection of single nucleotide polymorphism (SNP) by the TaqMan PCR assay using dried saliva on watersoluble paper and hair-rooTS, without DNA extraction. Anal Sci
2014; 30: 427-429.

16. Jansen H, Samani NJ, Schunkert H. Mendelian randomization studies in coronary artery disease. Eur Heart $J$ 2014; 35: 1917 1924.

17. Talmud PJ. How to identify gene-environment interactions in a multifactorial disease: CHD as an example. Proc Nutr Soc 2004; 63: $5-10$.

18. VanderWeele TJ, Knol MJ. A tutorial on interaction. Epidemiol Methods 2014; 3: 33.

19. Nakayama M, Yasue H, Yoshimura M, Shimasaki Y, Kugiyama $\mathrm{K}$, Ogawa $\mathrm{H}$, et al. T-786 $\rightarrow \mathrm{C}$ mutation in the 5'-flanking region of the endothelial nitric oxide synthase gene is associated with coronary spasm. Circulation 1999; 99: 2864-2870.

20. Ito $T$, Yasue $H$, Yoshimura $M$, Nakamura $S$, Nakayama $M$, Shimasaki Y, et al. Paraoxonase gene Gln192Arg (Q192R) polymorphism is associated with coronary artery spasm. Hum Genet 2002; 110: 89-94.

21. Murase Y, Yamada Y, Hirashiki A, Ichihara S, Kanda H, Watarai $\mathrm{M}$, et al. Genetic risk and gene-environment interaction in coronary artery spasm in Japanese men and women. Eur Heart $J$ 2004; 25: 970-977.

22. Nakano T, Osanai T, Tomita H, Sekimata M, Homma Y, Okumura K. Enhanced activity of variant phospholipase C-delta1 protein $(\mathrm{R} 257 \mathrm{H})$ detected in patienTS with coronary artery spasm. Circulation 2002; 105: 2024-2029.

23. Nakagawa H, Morikawa Y, Mizuno Y, Harada E, Ito T, Matsui $\mathrm{K}$, et al. Coronary spasm preferentially occurs at branch points: An angiographic comparison with atherosclerotic plaque. Circ Cardiovasc Interv 2009; 2: 97-104.

24. Murohara T, Kugiyama K, Ohgushi M, Sugiyama S, Yasue H. Cigarette smoke extract contracts isolated porcine coronary arteries by superoxide anion-mediated degradation of EDRF. Am J Physiol 1994; 266: H874-H880.

25. Reilly M, Delanty N, Lawson JA, FitzGerald GA. Modulation of oxidant stress in vivo in chronic cigarette smokers. Circulation 1996; 94: 19-25.

26. Kugiyama K, Yasue H, Ohgushi M, Motoyama T, Kawano H, Inobe $\mathrm{Y}$, et al. Deficiency in nitric oxide bioactivity in epicardial coronary arteries of cigarette smokers. J Am Coll Cardiol 1996; 28: $1161-1167$.

27. Ota Y, Kugiyama K, Sugiyama S, Ohgushi M, Matsumura T, Doi $\mathrm{H}$, et al. Impairment of endothelium-dependent relaxation of rabbit aortas by cigarette smoke extract--role of free radicals and attenuation by captopril. Atherosclerosis 1997; 131: $195-202$.

28. Ambrose JA, Barua RS. The pathophysiology of cigarette smoking and cardiovascular disease: An update. J Am Coll Cardiol 2004; 43: 1731-1737.

29. Messner B, Bernhard D. Smoking and cardiovascular disease: Mechanisms of endothelial dysfunction and early atherogenesis. Arterioscler Thromb Vasc Biol 2014; 34: 509-515.

30. Yoval-Sanchez B, Rodriguez-Zavala JS. Differences in susceptibility to inactivation of human aldehyde dehydrogenases by lipid peroxidation byproducts. Chem Res Toxicol 2012; 25: 722-729.

31. Chapple SJ, Cheng X, Mann GE. Effects of 4-hydroxynonenal on vascular endothelial and smooth muscle cell redox signaling and function in health and disease. Redox Biol 2013; 1: 319-331.

32. Mali VR, Palaniyandi SS. Regulation and therapeutic strategies of 4-hydroxy-2-nonenal metabolism in heart disease. Free Radic Res 2014; 48: 251-263.

33. Miyamoto S, Kawano H, Sakamoto T, Soejima H, Kajiwara I, Hokamaki J, et al. Increased plasma levels of thioredoxin in patients with coronary spastic angina. Antioxid Redox Signal 2004; 6: 75-80.

34. Itoh T, Mizuno Y, Harada E, Yoshimura M, Ogawa H, Yasue $\mathrm{H}$. Coronary spasm is associated with chronic low-grade inflammation. Circ J 2007; 71: 1074-1078.

35. World Health Organization. WHO Report on the global tobacco epidemic. 2008; 67176. http://www.who.int/tobacco/global_ report/summary/en/\# (accessed February 16, 2016).

36. Ma H, Guo R, Yu L, Zhang Y, Ren J. Aldehyde dehydrogenase 2 (ALDH2) rescues myocardial ischaemia/reperfusion injury: Role of autophagy paradox and toxic aldehyde. Eur Heart $J$ 2011; 32: 1025-1038 